\title{
Conical Hopper Design Parameters for Selected Food Powders using MS Excel Add-in
}

\author{
C.O.C. Oko \\ University of Port Harcourt. \\ Department of Mechanical \\ Engineering, College of \\ Engineering, PMB 5323, \\ Port Harcourt, Rivers State \\ Nigeria
}

\author{
E.O. Diemuodeke \\ University of Port Harcourt. \\ Department of Mechanical \\ Engineering, College of \\ Engineering, PMB 5323, Port \\ Harcourt, Rivers State Nigeria
}

\author{
D. Edet \\ University of Port Harcourt. \\ Department of Mechanical \\ Engineering, College of \\ Engineering, PMB 5323, \\ Port Harcourt, Rivers State \\ Nigeria
}

\begin{abstract}
This paper presents the design parameters for conical hopper, using MS Excel Add-in for hopper design, in the popular range of the wall friction angles for ten food powders in common use, and also correlates these parameters with the physical/flow properties of the powders. The design parameters are the opening diameter, critical applied stress, semi-included angle and the flow factor. The physical properties and direct shear test data of the ten food powders served as input parameters for computer based procedure developed for hopper design. The numerical results and correlations obtained are shown to be sufficiently accurate for engineering practice. They will enhance the efficient design of conical hoppers for these food powders.
\end{abstract}

\section{General Terms}

CAD for hoppers

\section{Keywords}

Conical hopper, Design parameters, Food powders, MS Excel

\section{INTRODUCTION}

The need for effective handling of large quantity and variety of food materials produced industrially in powdered form necessitated the introduction of hoppers for material handling. The complexity surrounding hopper design is mostly due to the mass flow ability, which depends principally on the mechanical behaviour of the stored material, semi-included angle, flow factor and the critical applied stress [1], [2]. Designing and troubleshooting mass flow hoppers require the measurement of powder flow [3], [4].

Powder properties significantly affect powder behaviour during storage, handling and processing [5], [6], [7], [8]. Therefore, powder flow property measurement is very important in handling and processing operations, such as flow from hoppers, transportation, mixing, compression, and packaging. Jenike [9] identified the properties that affect material flow in storage vessels and their measurement techniques. He also applied measured property data to twodimensional stress analysis to develop charts and a mathematical model for determining the minimum hopper angle and hopper exit opening size for material flow from conical and wedge-shaped hoppers. The geometrical characteristics of the hopper affect the rate of flow of the material out of the hopper [4], [10], [11], [12]. Jenike and Johanson [13] explained the various ways that grains might move during emptying, and the flow patterns that are developed. The advent of modern automated powder testing systems has simplified powder flow measurement, making it easier for users who are not instrument specialists to precisely determine the parameters required for hopper design [14], [15].

The trend in contemporary engineering practice is the application of computer technology to design processes that have well established procedure such as the Jenike's hopper design procedure. The development of the hopper design spreadsheet add-in for conical and wedge types of hopper by Oko et al [1] guides the engineers through the established methodologies to use measured powder flow data to generate design parameters, for powder or particulate flow hoppers. This development brings hopper design within the reach of the majority of process engineers, offering an opportunity to reduce costs and gain a better understanding of the factors influencing their performance.

Stasiak and Molenda [8] present data for direct shear testing of flowability of two groups of food powders used in industry: cereal powders (coarse flour, semolina, wheat groats, pearl barley groats and oat meal); and non-starch powders (icing sugar, table sugar, potato flour, powdered milk and table salt), which correctly show the flow properties of the food powders. But there are limited data for the key hopper design parameters for these powders. The key design parameters are: hopper opening diameter, D; semi-included angle, $\theta$; flow factor, ff; and critical applied stress, CAS [4].

Since hoppers are fabricated using various kinds of material, the wall friction angle, which is a major factor in the determination of semi-included angle, critical applied stress and flow factor, will vary once the effective angle of internal friction has been established for a particular powder.

Therefore, this paper applied the Oko et al [1] MS Excel Addin for hopper design to establish conical hopper design parameters for a range of wall friction angles (12 $\left.-29\left[{ }^{\circ}\right]\right)$ for ten food powders: coarse flour, semolina, wheat groats, pearl barley groats, oat meal, icing sugar, table sugar, potato flour, powdered milk and table salt based on the physical properties and direct shear test data presented in [8] by using a modification of the spreadsheet add-in developed by Oko et al [1]

\section{MATERIAL AND METHODS}

The design procedure for mass flow hoppers presented in Oko et al [1] is as follows:

(i) determine experimentally the wall friction angle, $\delta \mathrm{w}\left[{ }^{\circ}\right]$, and effective angle of internal friction, $\delta \mathrm{e}\left[{ }^{\circ}\right]$;

(ii) plot the measured shear stresses, $\tau[\mathrm{kPa}]$, and normal stresses, $\sigma[\mathrm{kPa}]$, at various consolidation stresses to give the yield locus; 
(iii) determine the unconsolidated yield strengths, UYS [kPa], and major consolidating stresses, MCS $[\mathrm{kPa}]$, from the yield loci as illustrated in Figure 1; determine the semi-

(iv) included angle, $\theta\left[{ }^{\circ}\right]$, and flow factor, ff [-], (from the already known wall friction angle and the effective angle of internal friction) with the aid of the Jenike's charts, which correlates the semi-included angle, flow factor and wall friction angle;

(v) plot the UYS against MCS to give the material flow function (MFF), and also plot the inverse flow factor, 1/ff; and determine the critical applied stress (CAS) as the intersection of MFF and 1/ff (MFF = 1/ff), Fig 2.

Once the effective angle of internal friction and MFF are determined for the powder, the wall friction angle is the only determining factor for the critical applied stress.

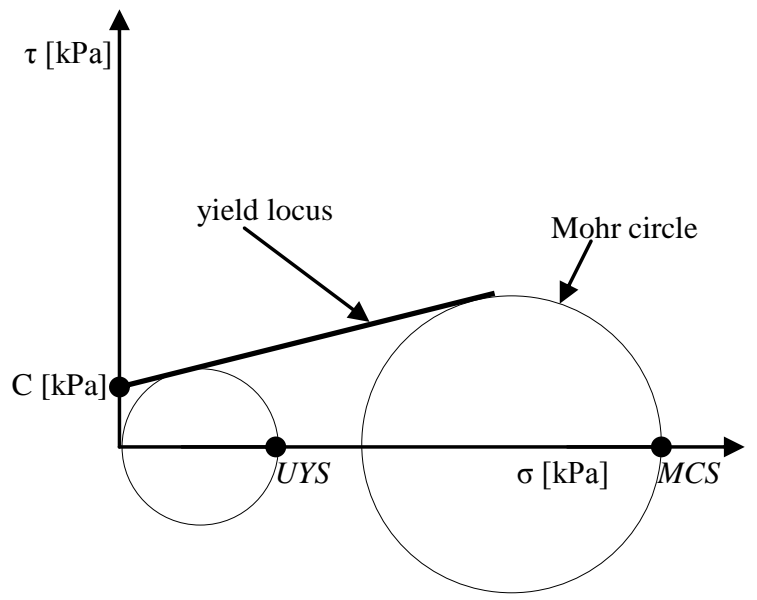

Fig 1 Determination of UYS and MCS from the yield locus

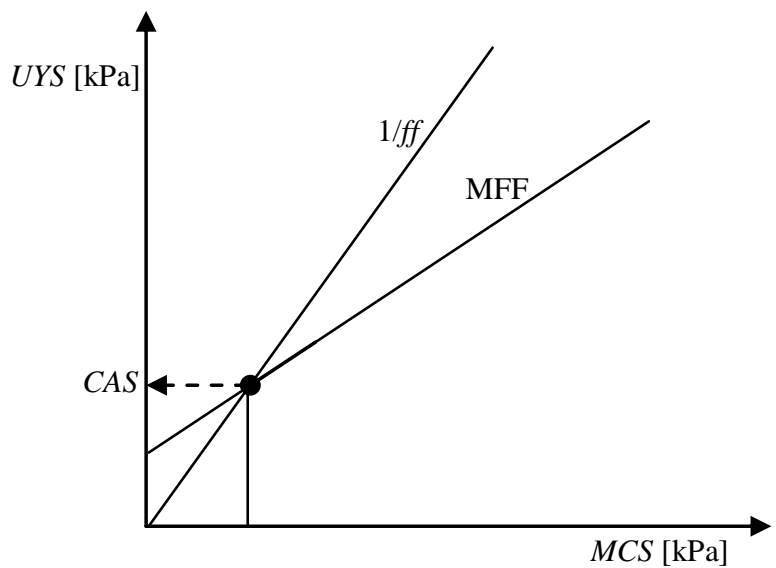

Fig 2 Determination of CAS from the interception of $1 / f f$ and MFF

The yield loci may be obtained by using the Mohr-Coulomb theory [4]. (Fitzpatrick et al 2004),

$$
\tau=\sigma \tan \varphi+c
$$

where $\varphi[\mathrm{o}]$ is the angle of internal friction; $\mathrm{c}[\mathrm{kPa}]$ is the cohesion of the powder; and $\sigma[\mathrm{kPa}]$ is the normal stress.

Considering Fig 1, one obtains the mathematical expressions for the unconsolidated yield strength (UYS) and the major consolidating stress (MCS), respectively, as
$U Y S=2 c(\sec \phi+\tan \phi)$

and

$$
M C S=-c \cot \phi+B\left(\sec ^{2} \phi+\sec \phi \tan \phi\right)
$$

where

$$
B=\sigma_{i}+c \cot \phi-\sqrt{\left(\sigma_{i}+c \cot \phi\right)^{2} \sin ^{2} \phi-\tau_{i}^{2} \cos ^{2} \phi} ;
$$

and $\sigma_{i}$ and $\tau_{i}$ are the normal and shear stresses, respectively, at any steady pre-shear point.

This present work modified and executed the hopper design algorithm presented by Oko et al [1], to make the MS Excel spreadsheet based mass flow hopper design procedure to be more flexible, and is presented as follows:

start

input data

(i) experimentally determined wall friction angle and effective angle of internal friction;

(ii) compacting stresses and corresponding unconfined yield stresses or applied stress experimentally known? yes then goto (iii) else goto (a);

(a) determine the yield loci from the angle of internal friction, cohesion and predetermined normal stresses;

(b) compute (using relevant relationships) compacting stresses and corresponding yield stresses;

(iii) bulk density, acceleration due to gravity;

compute (using the relevant relationships for the design parameters: $\mathrm{D}, \theta$, ff and CAS);

output data (output the design parameters): semi-included angle; flow factor; critical applied stress and discharge hopper diameter;

stop.

\section{RESULTS AND DISCUSSION}

Applying the modified MS Excel add-in for hopper design developed by Oko et al [1] to the experimental data for the wall friction angle, $\delta_{w}$, and the effective angle of internal friction, $\delta_{\mathrm{e}}$, provided by Stasiak and Molenda [8], the pertinent conical hopper design parameters were determined for the ten selected food powders. The values of these design parameters are tabulated in Table1; where $D, \theta, f f$ and $C A S$ are the exit diameter, semi-included angle; flow factor and critical applied stress, respectively.

Table 1 shows that table salt recorded the lowest value of hopper opening diameter, 0.271-0.279[m], and critical applied stress, $1.104-1.304[\mathrm{kPa}]$, whereas pearl barley groats has the largest values of opening hopper diameter, 4.073-4.228[m], and critical applied stress, $11.008-12.337[\mathrm{kPa}]$. The largest values of semi-included angle and flow factor were obtained for oat meal, $24.30-45.79\left[^{\circ}\right]$ and $1.83-2.43[-]$, respectively, while the lowest values were obtained for potato flour, 10.73 $36.00\left[^{\circ}\right]$ and $1.49-1.62[-]$, respectively. 
Table 1 Conical hopper design parameters for the selected food powders

\begin{tabular}{|c|c|c|c|c|c|}
\hline Food Powder & $\delta_{w}\left[{ }^{0}\right]$ & $D[\mathbf{m}]$ & $\theta\left[{ }^{0}\right]$ & $f f[-]$ & $C A S[\mathrm{kPa}]$ \\
\hline \multirow{4}{*}{ Coarse flour } & 12 & 0.637 & 41.15 & 2.06 & 1.504 \\
\hline & 15 & 0.639 & 35.97 & 2.00 & 1.557 \\
\hline & 17 & 0.639 & 32.12 & 1.94 & 1.600 \\
\hline & 21 & 0.612 & 23.46 & 1.83 & 1.704 \\
\hline \multirow{4}{*}{ Semolina } & 12 & 1.832 & 37.89 & 1.79 & 4.452 \\
\hline & 17 & 1.789 & 30.66 & 1.74 & 4.556 \\
\hline & 21 & 1746 & 2400 & 1.71 & 4652 \\
\hline & 26 & 1.681 & 14.59 & 1.66 & 4.791 \\
\hline \multirow{4}{*}{ Wheat groats } & 12 & 1.160 & 39.79 & 1.95 & -3.153 \\
\hline & 15 & 1.156 & 35.06 & 1.91 & -3.236 \\
\hline & 17 & 1.153 & 31.58 & 1.87 & -3.303 \\
\hline & 25 & 1.135 & 15.00 & 1.71 & -3.653 \\
\hline \multirow{4}{*}{ Pearl barley gro } & 12 & 4.228 & 38.69 & 1.86 & -11.008 \\
\hline & 15 & 4.202 & 34.29 & 1.82 & -11.254 \\
\hline & 17 & 4.182 & 31.08 & 1.80 & -11.439 \\
\hline & 25 & 4.073 & 15.98 & 1.70 & -12.377 \\
\hline \multirow{4}{*}{ Oat meal } & 12 & 0.752 & 45.79 & 2.43 & -1.185 \\
\hline & 15 & 0.787 & 58.67 & 2.23 & -1.297 \\
\hline & 17 & 0.819 & 33.29 & 2.09 & -1.397 \\
\hline & 20 & 0.887 & 24.30 & 1.83 & -1.606 \\
\hline \multirow{4}{*}{ Icing sugar } & 12 & 3.416 & 37.49 & 1.75 & 9.270 \\
\hline & 17 & 3.336 & 30.44 & 1.72 & 9.477 \\
\hline & 23 & 3.212 & 20.50 & 1.67 & 9.770 \\
\hline & 27 & 3.110 & 12.97 & 1.63 & 9.995 \\
\hline \multirow{4}{*}{ Table sugar } & 12 & 1.953 & 37.64 & 1.77 & 6.256 \\
\hline & 17 & 1.907 & 30.52 & 1.73 & 6.398 \\
\hline & 23 & 1.836 & 20.46 & 1.68 & 6.600 \\
\hline & 27 & 1.777 & 12.82 & 1.64 & 6.756 \\
\hline
\end{tabular}




\begin{tabular}{|c|c|c|c|c|c|}
\hline Food Powder & $\delta_{w}\left[{ }^{0}\right]$ & $D[\mathbf{m}]$ & $\theta\left[^{0}\right]$ & $f f[-]$ & $C A S[\mathrm{kPa}]$ \\
\hline \multirow{4}{*}{ Potato flour } & 12 & 1.810 & 36.00 & 1.62 & -4.677 \\
\hline & 21 & 1.744 & 23.74 & 1.56 & -4.892 \\
\hline & 23 & 1.726 & 20.67 & 1.54 & -4.948 \\
\hline & 29 & 1.687 & 10.73 & 1.49 & -5.069 \\
\hline \multirow{4}{*}{ Powder milk } & 12 & 1.697 & 36.91 & 1.70 & -3.672 \\
\hline & 21 & 1.659 & 23.93 & 1.64 & -3.755 \\
\hline & 23 & 1.602 & 20.61 & 1.62 & -3.869 \\
\hline & 29 & 1.555 & 9.72 & 1.58 & -3.956 \\
\hline \multirow{4}{*}{ Table salt } & 12 & 0.271 & 37.74 & 1.77 & 1.104 \\
\hline & 17 & 0.290 & 30.58 & 1.73 & 1.232 \\
\hline & 23 & 0.279 & 20.43 & 1.68 & 1.293 \\
\hline & 27 & 0.279 & 12.72 & 1.64 & 1.304 \\
\hline
\end{tabular}

Table 2 is obtained by applying the techniques of this presentation to salt 140 and 200, corn starch and flour, and tomato, which are among the food powders analysed by Fitzpatrick et al [4]. The data for the semi-included angle, $\theta$, flow factor, $f f$, and critical applied stress, $C A S$ are in good agreement.

The dependence of the hopper opening diameter and semiincluded angle on the effective angle of internal friction and wall friction angle for the coarse flour is shown in Fig 3. The hopper opening diameter, $D$, (the dashed lines) increases with an increasing effective angle of internal friction, $\delta_{e}$, for $\delta_{w}=$ 12 and $15\left[^{\circ}\right]$, but has a minimum value between $\delta_{e}=24$ and $28\left[^{\circ}\right]$ for $\delta_{w}=21\left[^{\circ}\right]$. On the other hand, the semi-included angle decreases, $\theta$, (continuous lines) decreases with increasing effective angle of internal friction, $\delta_{e}$, for $\delta_{w}=12$ and $15\left[^{\circ}\right]$, but increases with $\delta_{e}$ at $\delta_{w}=12\left[^{\circ}\right]$. The hopper opening diameter, $D$, increases with wall friction angle, $\delta_{w}$, up to the effective angle of internal friction, $\delta_{e}$, of $28\left[^{\circ}\right]$, where all the opening diameters are approximately equal, and thereafter the hopper opening diameter decreases with increasing wall friction angle, $\delta_{w}$.

Table 2 Design Parameters for Conical Hopper

\begin{tabular}{lccccc}
\hline $\begin{array}{l}\text { Food } \\
\text { Powder }\end{array}$ & $\delta_{w}\left[^{\circ}\right]$ & $D[\mathrm{~m}]$ & $\theta\left[^{\circ}\right]$ & $f f[-]$ & $\begin{array}{c}C A S \\
{[\mathrm{kPa}]}\end{array}$ \\
\hline Salt 140 & 27.3 & 0.032 & 14.10 & 1.20 & 0.01 \\
\hline $\begin{array}{l}\text { Corn } \\
\text { starch }\end{array}$ & 14.7 & 0.051 & 31.31 & 1.47 & 0.15 \\
\hline $\begin{array}{l}\text { Corn } \\
\text { flour }\end{array}$ & 13 & 0.020 & 31.04 & 1.29 & $\begin{array}{c}-0 . \\
06\end{array}$ \\
\hline Salt 200 & 26.2 & 1.005 & 17.26 & 1.17 & 3.75 \\
\hline Tomato & 20.7 & 0.043 & 21.81 & 1.11 & 0.160 \\
\hline
\end{tabular}

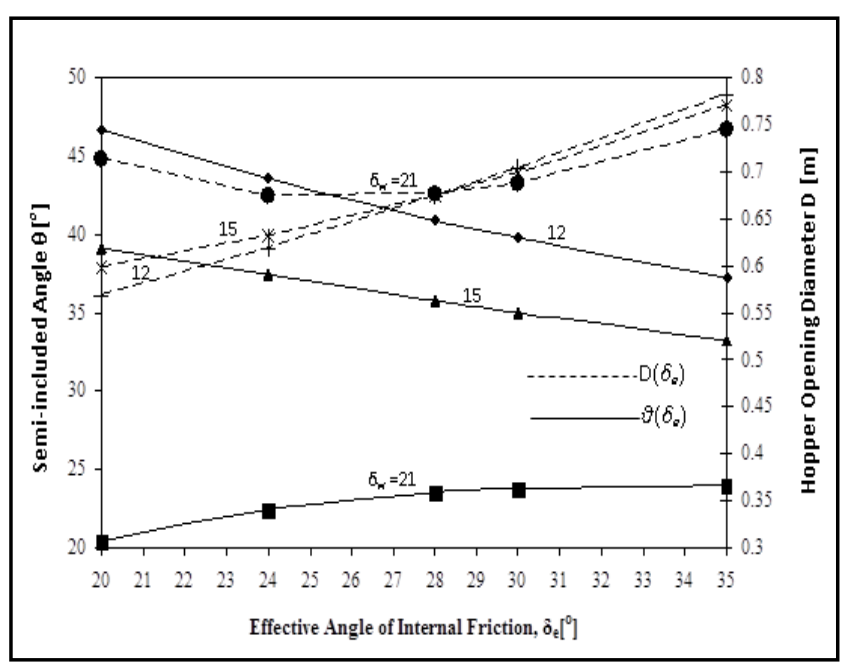

Fig 3 Relationships of semi-included angle and hopper opening diameter with effective angle of internal friction and wall friction angle for coarse flour

Similarly the coarse flour critical applied stress and flow factor as functions of the effective angle of internal friction and wall friction angle are shown in Fig 4. Here, the critical applied stress, CAS, (the continuous lines) increases with an increasing effective angle of internal friction, $\delta_{e}$, for $\delta_{w}=12$ and $15\left[^{\circ}\right]$, but has a minimum value between $\delta_{e}=24$ and $28\left[^{\circ}\right]$ for $\delta_{w}=21\left[^{\circ}\right]$. On the other hand, the flow factor, ff, (dashed lines) decreases monotonously with increasing effective angle of internal friction, $\delta_{e}$, for $\delta_{w}=12$ and $15\left[^{\circ}\right]$, but has a maximum value between $\delta_{e}=24$ and $28\left[^{\circ}\right]$ for $\delta_{w}=$ $21\left[^{\circ}\right]$. 


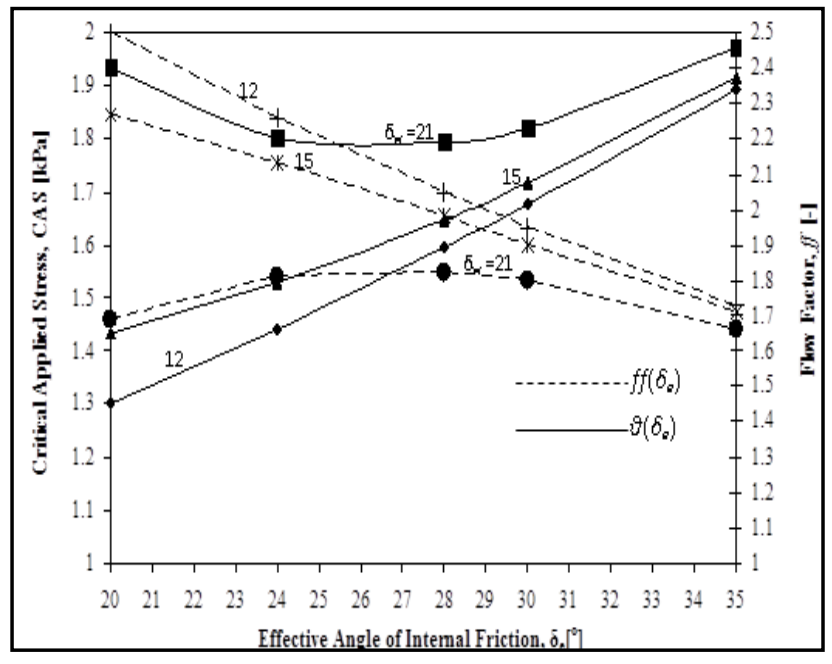

Fig 4 Relationships of critical applied stress and flow factor with effective angle of internal friction and wall friction angles for coarse flour

From Fig 3 and Fig 4 one obtains the correlations for the exit diameter, $D$, semi-included angle, $\theta$, flow factor, $f f$, and critical applied stress, CAS, for the coarse flour as functions of the wall friction angle, $\delta_{w}$, and effective angle of internal friction, $\delta_{e}$, as follows:

$$
\begin{aligned}
& D\left(\delta_{w}, \delta_{e}\right)=0.0076 \delta_{w}^{2} \delta_{e}^{2}-0.0005 \delta_{w}^{2} \delta_{e}-0.1451 \delta_{e}^{2} \delta_{w}+9 \times 10^{-6} \delta_{w}^{2} \\
& +1.0371 \delta_{e}^{2}+0.0096 \delta_{w} \delta_{e}-0.0002 \delta_{w}-0.0401 \delta_{e}+0.0015 \\
& \theta\left(\delta_{w}, \delta_{e}\right)=-0.1749 \delta_{w}^{2} \delta_{e}^{2}+0.0067 \delta_{w}^{2} \delta_{e}-1.7156 \delta_{e}^{2} \delta_{w}-2 \times 10^{-5} \delta_{w}^{2} \\
& +113.74 \delta_{e}^{2}+0.0823 \delta_{w} \delta_{e}+0.0002 \delta_{w}-3.2744 \delta_{e}+0.0413 \\
& f f\left(\delta_{w}, \delta_{e}\right)=-0.015 \delta_{w}^{2} \delta_{e}^{2}+0.009 \delta_{w}^{2} \delta_{e}+0.0436 \delta_{e}^{2} \delta_{w}-2 \times 10^{-5} \delta_{w}^{2} \\
& +5.7208 \delta_{e}^{2}-0.0051 \delta_{w} \delta_{e}+0.0002 \delta_{w}-0.1667 \delta_{e}+0.0006 \\
& \operatorname{CAS}\left(\delta_{w}, \delta_{e}\right)=0.0266 \delta_{w}^{2} \delta_{e}^{2}-0.0016 \delta_{w}^{2} \delta_{e}-0.53496 \delta_{e}^{2} \delta_{w}+2 \times 10^{-5} \delta_{w}^{2} \\
& +3.3704 \delta_{e}^{2}+0.0399 \delta_{w} \delta_{e}-0.0005 \delta_{w}-0.1572 \delta_{e}+0.0031
\end{aligned}
$$

By differentiating Equations (4) through (7) and finding the zeros of the resulting expressions, the extremal values of the opening diameter, $D^{*}$, critical applied stress, $C A S^{*}$, semiincluded angle, $\theta^{*}$, and flow factor, $f f *$, are obtained as: min $(D)=D^{*}=0.68[\mathrm{~m}]$ at $\delta_{e}^{*}=25.6\left[{ }^{\circ}\right] ; \min (C A S)=C A S^{*}=$ $1.78[\mathrm{kPa}]$ at $\delta_{e}^{*}=25.6\left[^{\circ}\right]$; $\max (\theta)=\theta^{*}=25.01\left[^{\circ}\right]$ at $\delta_{e}^{*}=$ $32.78\left[^{\circ}\right]$; and $\max (f f)=f f *=1.82[-]$ at $\delta_{e}^{*}=25.6\left[^{\circ}\right]$.

\section{CONCLUSION}

This paper has presented the conical hopper design parameters, using an MS Excel Add-in for hopper design, for ten popular food powders: coarse flour, semolina, wheat groats, pearl barley groats, oat meal, icing sugar, table sugar, potato flour, powdered milk and table salt based on the specified physical properties and direct shear test data. The results obtained cover the range of wall friction angles $12-$ $29\left[^{\circ}\right]$. Although there were no direct means of comparing all the results obtained with those in the literatures, the results of the conical hopper design parameters presented by Fitzpatrick et al [4] for some food powders (salt 140 and 200, corn starch and flour, and tomato) compare favourably with the results obtained with our technique. Simulations have also been carried out to study the interrelationships between the design parameters and the physical properties of the powders, and correlations for such study were also obtained. The data presented in this work will enhance the efficient design of conical hoppers for handling any of the ten food powders considered.

\section{REFERENCES}

[1] Oko, C.O.C., Diemuodeke, E.O., Akinlade, I.S. 2010 "Design of hopper using spreadsheet add-in", Research in Agric. Eng. 56(2), $53-58$.

[2] Kaye, B.H. 1997 "Characterizing the flowability of a powder using the concepts of fractal geometry and chaos theory", Particle and Particle System Characterisation 14, $53-66$.

[3] Bell T.A. 1999. "Industrial needs in solids flow for the 21 st Century", Journal of Powder Handling and Processing 11, 9-12.

[4] Fitzpatrick, J., Barringer, S.A., Iqbal, T. 2004. "Flow property measurements of food powders and sensitivity of Jenike's hopper design methodology to the measured values", Journal of Food Engineering 61, 399 - 405.

[5] Peleg, M. 1978. “Flowability of food powder and methods for it evaluation-A review", Journal of Food Process Engineering 1, $303-328$.

[6] Rhodes, M. 1990 "Principles of powder technology", John Wiley, New York.

[7] Knowlton, T.M. 1984. "The importance of storage, transfer and collection", Chemical Engineering Progress $90,44-54$

[8] Stasiak, M., Molenda, M. 2004. "Direct shear testing of flowability of food powders" Research in Agric. Eng. 50(1), $6-10$.

[9] Jenike, A.W. 1964. "Storage and flow of solids", Bulletin No. 123, Engineering Experiment Station, University of Utah.

[10] Bridgwater, B.N., Scott, H.C. 1983. "Static and dynamic silo loads using FEMs". Journal of Agric. Eng 78(3), $299-308$.

[11] Griffith, M.S. 1991. "Cake formation in particulate systems. VCH Publishers”, New York.

[12] Holdich, R. 2002. "Fundamentals of particulate technology. Midland", Loughborough.

[13] Jenike, A.W., Johansson, J.R. 1984. Bin loads. Journal of Structures, Div. ASCE 94(ST4), 1011-1041.

[14] Emery, E. 2008. "Flow properties of selected pharmaceutical powders", M. Sc. Thesis, Department of Chemical Engineering, University of Saskatchewan, Saskatchewan.

[15] Drescher, A., Waters, A.J., Rhoades, C.A. 199. “Arching in hoppers: I. Arching theories and bulk material flow properties", Powder Technology 84, $165-176$. 